\title{
Delivering clinical preventive services in the Islamic Republic of Iran: A model for screening and behavior consultation practices
}

\author{
Soodabeh Hoveidamanesh ${ }^{1}$, Farnoush Davoudi*2, Jalil Koohpayehzadeh ${ }^{2}$, Marzieh Nojomi ${ }^{3}$
}

Received: 13 May 2017

Published: 14 Dec 2018

\begin{abstract}
Background: Screening and behavior consultation are considered to be limited, dispersed and expensive services across the country. To deliver efficient and equitable services current disordered practices need to be consolidated.

Methods: An analysis of current situation, learned lessons and future scopes of country's preventive care delivery, along with a review of international experience and generous participation of various stakeholders, led to proposing a model for screening and behavior consultation practices in IR. Iran.

Results: Upon the results of the previous steps, the desired model was based on the network system and family physician. Comprehensive health centers and other centers affiliated to the network are the most appropriate service positions. However, private and academic preventive centers are playing their rules.

Conclusion: The proposed model matches the overall pattern of service delivery in the health system (network system with the private sector and the educational sector).
\end{abstract}

Keywords: Preventive health service, Health care delivery, Health risk assessment, Behaviors, Risk reduction

Conflicts of Interest: None declared

Funding: None

*This work has been published under CC BY-NC-SA 1.0 license.

Copyright $\odot$ Iran University of Medical Sciences

Cite this article as: Hoveidamanesh S, Davoudi F, Koohpayehzadeh J, Nojomi M. Delivering clinical preventive services in the Islamic Republic of Iran: A model for screening and behavior consultation practices. Med J Islam Repub Iran. 2018 (14 Dec);32:125. https://doi.org/10.14196/mjiri.32.125

\section{Introduction}

Evidence-based preventive strategies are the key to reducing death and disability and improving the nation's health. Along with the well-known primary, secondary and tertiary classification, preventive interventions fall into major categories of community and clinical services (1).

Community preventive services are best resembled by population-based interventions such as tobacco cessation and increasing physical activity within communities. The activities could be held in different community settings.

Clinical preventive services (CPSs) are delivered in clinical settings, to prevent the onset or progression of

\footnotetext{
Corresponding author: Dr Farnoush Davoudi, davoudi.f@iums.ac.ir

1. Preventive Medicine and Public Health Research Center, Iran University of Medical Sciences, Tehran, Iran

2. Preventive Medicine and Public Health Research Center, Department of Community Medicine, School of Medicine, Iran University of Medical Sciences, Tehran, Iran

3. Preventive Medicine and Public Health Research Center, Department of Community Medicine, School of Medicine, Iran University of Medical Sciences, Tehran, Iran, \& Academy of Medical Sciences of Islamic Republic of Iran, Tehran, Iran
}

health-threatening conditions. These services include immunization, screening, behavior consultation and chemoprophylaxis (1-3). Some references tend to add minor surgical interventions (i.e., circumcision) to the list (4).

CPSs are found to be cost-effective and even costsaving interventions (5-7) which can reduce common causes of disability and mortality $(8,9)$. But, studies show that the CPSs delivered by many health systems do not meet the population's needs in terms of coverage and utilization $(4,10-18)$.

IR Iran's Ministry of Health (MOH) has been deliver-

\section{$\uparrow$ What is "already known" in this topic:}

Clinical Preventive strategies are the key to reducing death and disability and improving health. CPSs are found to be costeffective and even cost-saving interventions.

\section{$\rightarrow$ What this article adds:}

PHC system with its rural and urban infrastructures in addition to affiliated family physicians is the suggested platform to deliver CPSs. Private HPPCs seem to have a minimal role in delivering any CPSs in future. 
ing Immunization and chemoprophylaxis as public health services for more than four decades. But there has been much debate in recent years about screening and behavior consultation (SBC) practices. The main goal of this manuscript is presenting our designed model for SBC in IR Iran.

\section{The existing situation}

In late 2016 - early 2017, Primary Health Care (PHC) centers were providing the scant SBCs mandated in the national essential health service package. General practitioners and specialist working in the private sector, offered very selective SBC services upon patients' request or certain clinical suspicion. Health Promotion and Preventive Clinics (HPPCs), introduced a few years earlier to encourage comprehensive clinical preventive care including $\mathrm{SBCs}$ in teaching hospitals and the private sector, were no more than a failed initiative.

Government's healthcare spending per capita covered the cost of SBCs delivered by PHC. Social insurances had a restrictive stance on covering preventive care costs. People had to pay throughout of pocket and/or private insurances for the majority of evidence-based recommended SBCs.

\section{The Argumentation}

The research team performed a sensitive search of national and international electronic databases and web pages in addition to library archives of $\mathrm{MOH}$ and Universities of Medical Sciences to attain information about SBC delivery experiences, learned lessons and future scopes across different health systems.

The evidence gathering proceeded with conducting indepth semi-structured interviews with twelve health care delivery experts and major clinical preventive service providers, representing all type of service deliveries across the country. The respondents were to share their own ex- periences, express their viewpoints and comment on the finding of the literature review.

A Stakeholder analysis by reviewing existing information and interviewing priority stakeholders identified beneficiaries of SBC practices according to their power, interest, and readiness for change.

The findings were summarized into separate lists addressing major concerns in health care delivery models. A panel of experts consisting of health system managers, policy makers, economists and administrators reviewed and discussed the summaries. Inapplicable findings or poorly advocated statements were excluded from the lists, and the remaining suggestions were prioritized. Thus the preliminary model was prepared. Seven experts, independent from the above-mentioned panel, reviewed and refined the draft. Figure 1, is the graphical communication of the final model.

\section{Drawing the path forward}

The following is a synopsis of rationales for every proposed component of the model.

\section{The platform for change}

The expert panels' members were unanimous that providing any health care services including SBC had to be in adherence to country's current health care delivery system. It was strongly advised against proposing any infrastructures or legislations beyond existing ones.

The challenge was that a health care reform was launching at the time to establish an effective referral system through Family physician initiative. The solution was to propose a flexible model consisting of "main" and "alternative" options. The "main" options were the desired ones to be in action by the time of complete establishment of the new health care system. The alternatives were to be applied during various stages of the transitional phase.

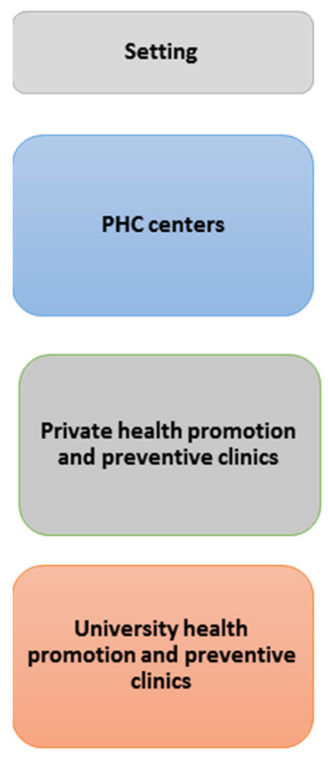

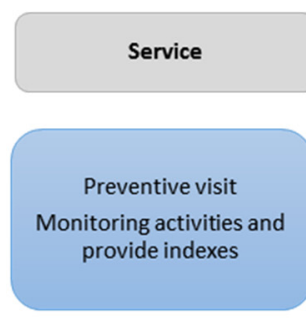

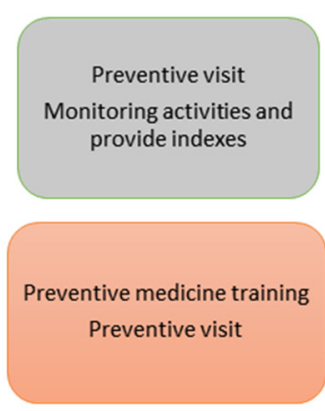

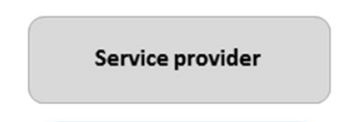

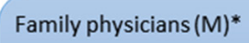

Trained general physicians(A)** Trained health care providers(A)

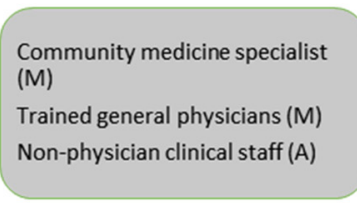

Community medicine specialist (M)

clinicians physicians of department of Community Medicine / family physicians (A)
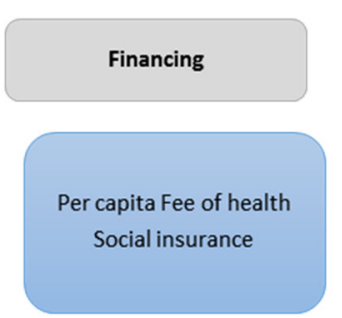

Social insurance (M) Private insurance $(A)$ Out of pocket (A)

Social insurance (M) Private insurance (A) Copayment (A)
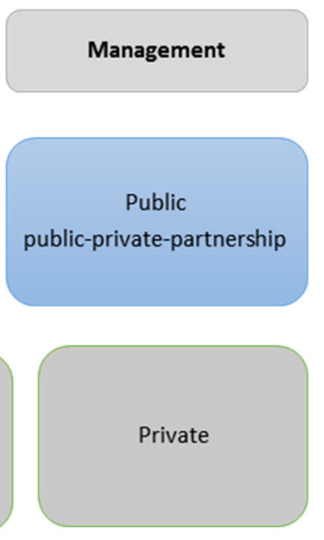

Public

Fig. 1. Proposed model for screening and behavior consultation practices in IR. Iran *Main

** Alternative 


\section{SBC in CPS providing facilities}

PHC centers are to be the settings of choice to deliver SBC services to individuals along with collecting and analyzing regional data. This has been proposed based on the fact that the PHC system is not only the country's infrastructure for health care delivery, but also the gate to reach universal health coverage and promote health equity.

Private HPPCs seem to have a minimal role in delivering any CPSs in the future. This assumption is made based on health system perspective implying that after the complete establishment of Family Physician initiative, walk-in visits to the private sector would significantly drop.

On the other hand, HPPCs in teaching hospitals, along with their essential role in training medical students in the field of preventive medicine, provide unique opportunities for SBC services. Individuals and groups who do not refer to $\mathrm{PHC}$ system may reach CPSs including SBC there. These clinics could also be cornerstones of communityclinical integration activities aimed at deployment and success of clinical prevention.

\section{SBC delivery and Health Professionals}

In clinical care, risk assessment and management, behavior modification, counseling, and health promotion are the primary tasks of physicians. While a wide range of non-physician health workers has contributed to PHC's cost-efficient clinical prevention over decades. Therefore SBC services in PHC centers, are assumed to be delivered by a "team" of family physicians and general physicians as well as other health care workers. Other SBC providers are encouraged to consider the "team" approach as well.

Private HPPCs are physician-centered practices. They mandate to have at least one community and preventive medicine specialist and a general physician in every work shift. These clinics might contract other specialists to provide SBC too. Considering changes in patient referral and payment systems aimed by the current health reform, there is still room for doubt about specialists' interest in providing CPSs at private HPPCs.

Teaching hospitals' HPPCs are to be run by faculty members of affiliated departments of community and preventive medicine - family physician. Like other teaching clinics, residents, interns and medical students are involved in care delivery.

\section{Paying for SBC services}

Given that SBC services are to be integrated into the PHC system, all care costs should be covered through government healthcare spending per capita and social insurances. Private insurance and out of pocket payments have to be limited to services not recommended by national Clinical prevention guidelines. Such strategies tend to maximize equitable CPSs and prevent overutilization of services.

\section{The Government's role}

While SCBs delivery facilities could be run by either of public or private sectors, or through public-private partnership, $\mathrm{MOH}$, as a part of its constitutional duty of governance across the health system, strategically directs service organization and behavior of health care financiers and providers regarding SBC.

The government is also responsible for SCB care supporting processes such as training the workforce, integrating health information technology into CPS, developing national guidelines for comprehensive health risk assessment and preventive interventions, monitoring, and evaluation of the whole national clinical prevention programs, guiding research activities in addition to medical logistics support. The MOH might assign to contract other parties supporting the processes.

\section{The real challenge}

Integration of SCB into PHC is the preferred perspective of most experts and authorities, including $\mathrm{MOH}$ as the provider and financier of PHC services. It is assumed that the current health reform would result in universal coverage of preventive care and eliminated out of pocket payments.

But the real challenge arises when you note that national essential health service package services do not include a majority of age-sex specific recommended SBCs. The package has to be expanded so do financial resources!

\section{Conclusion}

The authors hereby, proposed a model for screening and behavior consultation practices in the I.R. of Iran. The model is not only conceptualized based on grand principals of health service delivery but also designed pragmatically in response to current and prospected characteristics of the country's health system.

SBC needs to be integrated into national essential health service package and delivered through public funded mechanisms. PHC system with its rural and urban infrastructures in addition to affiliated family physicians is the suggested platform to deliver SBCs.

Sound evidence regarding national SBC needs and priorities is required to persuade policy-makers to expand the current care package. The most cost-efficient preventive approaches need to be identified for each priority to reduce the financial burden of the health system. Strong advocacy strategies are required to win health financiers' and service purchasers' favor.

\section{Conflict of Interests}

The authors declare that they have no competing interests.

\section{References}

1. Krist AH, Shenson D, Woolf SH, Bradley C, Liaw WR, Rothemich $\mathrm{SF}$, et al. Clinical and community delivery systems for preventive care: an integration framework. Am J Prev Med. 2013 Oct;45(4):50816.

2. Fletcher R, Fletcher S, Fletcher G. Clinical Epidemiology The Essentials. Fifth ${ }^{\text {ed }} 2014$.

3. Krist A, Shenson D, Woolf S, Bradley C, Liaw W, Rothemich S. A Framework for integration of community and clinical care to improve the delivery of clinical preventive services among older adults. A report prepared for the National Association of Chronic Disease Direc- 
tors and the Michigan Public Health Institute, July. 2012. Available from: https://www.cdc.gov/aging/pdf/cps-integration-framework.pdf.

4. Stone PW, Teutsch S, Chapman RH, Bell C, Goldie SJ, Neumann PJ. Cost-utility analyses of clinical preventive services: published ratios, 1976-1997. Am J Prev Med. 2000 Jul;19(1):15-23.

5. Neumann P, Cohen J. Cost savings and cost-effectiveness of clinical preventive care. The Synthesis project Research synthesis report. 2009 Sep; 18.

6. Maciosek MV, LaFrance AB, Dehmer SP, McGree DA, Flottemesch TJ, Xu Z, et al. Updated Priorities Among Effective Clinical Preventive Services. Ann Fam Med. 2017 Jan;15(1):14-22.

7. Dehmer SP, Maciosek MV, LaFrance AB, Flottemesch TJ. Health Benefits and Cost-Effectiveness of Asymptomatic Screening for Hypertension and High Cholesterol and Aspirin Counseling for Primary Prevention. Ann Fam Med. 2017 Jan;15(1):23-36.

8. Farley TA, Dalal MA, Mostashari F, Frieden TR. Deaths preventable in the U.S. by improvements in use of clinical preventive services. Am J Prev Med. 2010 Jun;38(6):600-9.

9. Frieden TR. Use of Selected Clinical Preventive Services Among Adults--United States, 2007-2010 MMWR supplements. 2012 Jun $15 ; 61(2): 1-2$

10. Krist AH, Aycock RA, Etz RS, Devoe JE, Sabo RT, Williams R, et al. My Preventive Care: implementation and dissemination of an interactive preventive health record in three practice-based research networks serving disadvantaged patients--a randomized cluster trial. Implement Sci. 2014; 9(1):181.

11. Fox JB, Shaw FE. Relationship of income and health care coverage to receipt of recommended clinical preventive services by adults United States, 2011-2012. MMWR Morbidity and mortality weekly report. 2014 Aug 8;63(31):666-70.

12. McElwaine KM, Freund M, Campbell EM, Knight J, Bowman JA, Doherty EL, et al. The delivery of preventive care to clients of community health services. BMC Health Serv Res. 2013;13:167.

13. Bharmal N, Chaudhry S. Preventive health services delivery to South Asians in the United States. J Immigr Minor Health. 2012 Oct;14(5):797-802.

14. Crabtree BF, Miller WL, Tallia AF, Cohen DJ, DiCicco-Bloom B, McIlvain HE, et al. Delivery of clinical preventive services in family medicine offices. Ann Fam Med. 2005 Sep-Oct;3(5):430-5.

15. McGlynn EA, Asch SM, Adams J, Keesey J, Hicks J, DeCristofaro A, et al. The quality of health care delivered to adults in the United States. N. Engl. J. Med. 2003;348(26):2635-45.

16. Khoong EC, Gibbert WS, Garbutt JM, Sumner W, Brownson RC. Rural, suburban, and urban differences in factors that impact physician adherence to clinical preventive service guidelines. J Rural Health. 2014 Winter;30(1):7-16.

17. Lantz PM, Evans WD, Mead H, Alvarez C, Stewart L. Knowledge of and Attitudes toward Evidence-Based Guidelines for and Against Clinical Preventive Services: Results from a National Survey. Milbank Q. 2016 Mar;94(1):51-76.

18. Stolp H, Fox J. Increasing Receipt of Women's Preventive Services. J Womens Health (Larchmt). 2015 Nov;24(11):875-81. 